\title{
O PROCESSO DE HOMINIZAÇÃO: FREUD INTERPRETANDO NIETZSCHE
}

\section{The hominization process: Freud interpreting Nietzsche}

Fernanda Silveira Corrêa ${ }^{1}$

\section{Resumo}

O presente artigo relaciona as concepções filogenéticas freudianas com as concepções sobre a formação da cultura apresentadas por Nietzsche em a Genealogia da moral. Analisamos o mito filogenético da era glacial enviado por Freud a Ferenczi em 1915 e relacionamos cada uma de suas partes com as teses nietzscheanas. Interpretamos as duas partes do mito - a primeira, correspondente às vivências da humanidade na era glacial que criaram as condições para a formação da psicologia do pai primitivo e da horda primitiva, e a segunda, comespondente às vivências dos filhos submetidos ao poder do pai primitivo que criaram as condições para 0 ato parricida e a constituição da cultura - a partir da diferença proposta por Nietzsche entre credores e devedores, entre a moral dos senhores e a moral dos escravos. A comparação com as teses de Nietzsche possibilita-nos delinear aspectos do pai primitivo freudiano que estão ausentes no texto principal de Freud sobre a filogênese: Totem e tabu, mas que estão presentes em textos posteriores ao mito da era glacial. Evidencia o pai primitivo como um serlivre, um artista capaz de daruma forma a si mesmo e constituira horda. Por outro lado, tal comparação revela a lógica entre a vivência dos filhos de serem castrados e a disposição que ela constitui, o prazer na dor. Mostrada a correspondência entre as duas teorias interpretamos o próprio texto Totem e tabu, ou melhor, o mito do parricídio, como uma interpretação, uma complementação de Freud à genealogia nietzscheana.

Palavras-chave: Freud; Psicanálise; Filogênese; Cultura; Genealogia da moral.

1 Doutoranda em filosofia na UNICAMP, mestre em filosofia pela UNICAMP, professora da UNIP.

E-mail: fernandascorrea@terra.com.br

Revista de Filosofia, Curitiba, v. 17 n.20, p. 85-98, jan./jun. 2005. 


\section{Abstract}

The present article relates Freud's phylogenetic conceptions with the conceptions on culture formation presented by Nietzsche in the Genealogy of Morals. The Ice Age phylogenetic myth sent by Freud to Ferencze in 1915 is analyzed and each one of its parts is related with the Nietzsche's thesis. The division of the myth in two parts - the first one, corresponding to the human experiences in the Ice Age that created the conditions for the psychology formation of the primitive father and the primitive horde, and the second, corresponding to the experiences of the sons submitted to the power of the primitive father that created the conditions for the parricide's act and the constitution of the culture - is analyzed from the difference proposed by Nietzsche between creditors and debtors, between the moral of the aristocrat and moral of the slaves. The comparison with the Nietzschean thesis makes possible to delineate aspects of the Freud's primitive father that are absent in the Freud's main text on phylogenetic History: Totem and tabo o, but that are present in later texts about the Ice Age myth. It shows the primitive father as a free being, an artist capable to give form to himself and to constitute the horde. On the other hand, such comparison discloses the logic between the son experience to be castrated and the disposal that it constitutes, the pleasure in pain. After showing the correspondence between the two theories we interpret the own text Totem and taboo, or better, the myth of the parricide, as an interpretation, as a Freud's complementation to the Nietzsche's genealogy. Keywords: Freud; Psychoanalysis; Philogenesis; Culture; Moral's genealogy.

\section{Introdução}

Pretendemos, neste artigo, mostrar a pertinência de uma interpretação do mito filogenético enviado por Freud, em 1915, a Ferenczi (contido em: Freud, Neuroses de transferên cia: uma síntese. Manuscrito recém-descoberto como um diálogo de Freud com as teses nietzschianas sobre a formação da cultura apresentadas na segunda dissertação da Genealogia da moral).

O mito filogenético a que nos referimos foi escrito por Freud dois anos depois de terminado e publicado Totem e tabu e remete a um tempo anterior ao concebido, em Totem e tabu, como formador da cultu-

Revista de Filosofia, Curitiba, v. 17 n.20, p. 85-98, jan./jun. 2005. 
ra, a um tempo anterior ao parricídio. No mito enviado a Ferenczi, o crime parricida é apresentado como um ato conclusivo impulsionado pelas disposições anteriormente formadas devido a mudanças da era glacial. Muitas das teses sobre a filogênese apresentadas no mito são assumidas por Freud em textos posteriores como Psicologia das massas e análise do eu (1921), Mal estar na cultura (1938) e O Homem Moisés e a religião monoteísta (1929). Portanto, o fato de Freud não ter publicado o mito não significa que não tenha assumido suas hipóteses.

No mito do manuscrito, Freud apresenta seis fases que a humanidade teria passado a partir da era glacial, nas quais teriam sido constituídas as disposições presentes nos neuróticos (a intenção original do mito é finalizar uma discussão sobre as neuroses de transferência), mas presentes também em todos os seres humanos. As neuroses na verdade apenas intensificam disposições universais.

Nesse sentido, encontramos no mito do manuscrito uma relação direta entre a história filogenética da humanidade e a constituição do aparelho psíquico. Encontramos nele, na verdade, a constituição filogenética do que foi concebido como constitucional na ontogênese nos textos Projeto de uma psicologia científica (1895) (que chamarei daqui por diante de Projeto), no capítulo VII da Interpretação dos sonhos (1900), nos Três ensaios sobre a sexualidade (1905). Isso faz com que o mito constitua uma espécie de síntese do pensamento metapsicológico de Freud.

Justifico a alusão a Nietzsche, para a compreensão do mito, não só devido à semelhança das duas teorias no que diz respeito à interpretação da moral, o retorno da agressividade contra si mesmo, não só baseada na afirmação de Freud, em uma entrevista de 1926, de que Nietzsche teria sido o primeiro psicanalista, mas principalmente devido à interpretação que Freud oferece do pai primitivo na sua primeira alusão a ele depois de escrito o mito. Cito Freud:

"o pai da horda primitiva era livre. Seus atos intelectuais eram também, no isolamento, fortes e independentes, sua vontade não precisava da corroboração da dos outros ... No início da história da humanidade ele era o além-do-homem (Übermensch), que Nietzsche esperava apenas no futuro" (FREUD, 1982, p. 115.).

Esta citação de Freud não deixa dúvidas de que suas reflexões sobre a origem da cultura são fortemente influenciadas pelas reflexões de Nietzsche. Se nós retirarmos, como quer Freud, a dimensão futura do

Revista de Filosofia, Curitiba, v. 17 n.20, p. 85-98, jan./jun. 2005. 
além-do-homem de Nietzsche, creio que podemos encontrá-lo na concepção do nobre, do forte, daquele que não é ressentido, mas, se quisermos ir mais longe, e enviá-lo à pré-história, podemos identificá-lo com os próprios formadores da cultura, concebidos por Nietzsche. Aliás, não é difícil perceber nas características do pai primitivo, descritas no mito enviado a Ferenczi, a semelhança com as bestas louras descritas por Nietzsche: "homens livres", "independentes", "artistas", "intelectualmente livres", "com vontade própria", "com força para organizar e imprimir forma no animal humano", "violentos em atos e gestos", "os mais involuntários e inconscientes artistas, regidos pelo tremendo egoísmo dos artistas", "capazes de dar forma a si mesmo e à comunidade", dominadores de si e das circunstâncias, isto é, dominadores da natureza e dos mais fracos, credores dos que vivem sob sua proteção (NIETZSCHE, 1998).

\section{Desenvolvimento}

Passamos então à descrição das fases do mito, apontando suas semelhanças com a metapsicologia freudiana e com as concepções nietzschianas da segunda dissertação da Genealogia da moral.

As três primeiras fases remetem à constituição psicológica do pai primitivo, aquilo que em Psicologia das massase análise do eu (1921) Freud chamou de psicologia do indivíduo (em oposição à psicologia das massas). Na primeira fase, segundo Freud, devido aos perigos advindos da era glacial, os seres humanos optaram por não satisfazer seus impulsos sexuais e transformaram sua libido em angústia (Angst, traduziremos por angústia por consideramos esta tradução já consolidada, apesar de julgarmos que, no texto de Freud, medo é a melhor tradução para Angst). Nessa fase, foi constituída a disposição para a histeria de angústia, isto é, a angústia de anseio, de saudade (Sehnsuchtangst), que nada mais é que uma transformação da libido insatisfeita. Comparando com a metapsicologia freudiana, podemos dizer que essa característica corresponde à ausência, no recém-nascido, de imagens de movimento capazes de satisfazer seus impulsos, seus instintos (Triebe), idéia presente no Projeto (1895), no que diz respeito à fome, mas também presente nos Três ensaios sobre a sexualidade (1905), referindo-se a precocidade da excitação sexual (excitação que surge antes da capacidade de cumprir a função sexual). Nessa fase, portanto, a ação determinada pelo impulso, pelo

Revista de Filosofia, Curitiba, v. 17 n.20, p. 85-98, jan./jun. 2005. 
instinto foi contida. A angústia é, portanto, o sinal dessa impossibilidade (voluntária ou inata) de satisfazer por meio de uma ação os instintos.

Em Nietzsche aparece uma idéia muito similar, mas apresentada como efeito da vida em sociedade. Podemos supor que nas fases apresentadas no mito, Freud analisa separadamente distintas características expostas em conjunto por Nietzsche, isola cada uma delas e as dispõe em uma seqüência. É evidente que ao fazer isso, efetua alterações que tornam no final a teoria freudiana incompatível com a nietzschiana, no entanto tal incompatibilidade final não nega o solo comum original. A passagem de Nietzsche, que cremos apoiar-se Freud, é a seguinte:

"ocorreu a esses semi-animais adaptados de modo feliz à natureza selvagem, à vida errante, à guerra, à aventura, subitamente seus instintos ficaram sem valor e suspensos." (NIETZSCHE, 1887, p.72)

Nietzsche compara esse acontecimento com a mudança de hábitat dos animais, na evolução, da água para a terra:"o mesmo que deve ter sucedido aos animais aquáticos, quando foram obrigados a tornar animais terrestres ou perecer". "A partir de então deveriam andar com os pés e carregar a si mesmos, quando antes eram levados pela água: havia um terrível peso sobre eles" (NIETZSCHE, 1887, p 72).

Similar a necessidade de andar sobre os próprios pés é a necessidade de guiar-se sem os antigos guias que eram os instintos. "Nesse novo mundo não mais possuíam os seus velhos guias, os impulsos reguladores e inconscientemente certeiros" "e os velhos instintos não cessaram de fazer suas exigên cias” (NIETZSCHE, 1887, p. 73).

Podemos então dizer que nesta primeira fase a humanidade perdeu seus guias, no caso, os instintos sexuais, e tornou-se angustiada, pois os instintos não satisfeitos pela ação continuaram a fazer suas exigências.

Na segunda fase filogenética se constituiu a sexualidade perversa. Sexualidade que, como foi exposto nos Três ensaios sobre a sexualidade (1905), caracteriza a sexualidade inata, constitucional do ser humano. Podemos supor que essa fase corresponde, em Nietzsche, ao surgimento do mundo interior:

Todos os instintos que não se descarregam para fora voltam-se para dentro - isto é o que eu chamo de interiorização do homem: é assim que no homem cresce o que depois se denomina sua 'alma'. Todo o mundo interior, originalmente delgado, como que entre duas mem-

Revista de Filosofia, Curitiba, v. 17 n.20, p. 85-98, jan./jun. 2005. 
branas, foi se expandindo, adquirindo profundidade, largura e altura, na medida em que o homem foi inibido em sua descarga para fora (NIETZSCHE, 1887, p. 73).

O resultado final dessa fase é a criação de uma medida própria de valor, ela seria, portanto, a condição para que o ser humano se converta em um animal avaliador:

"o homem [Mensch] designava-se como o ser que mede valores, valora e mede, como `o animal avaliador" (NIETZSCHE, 1887, p. 59).

Nos termos de Freud, a medida de valor é dada pelo desejo, ou melhor, pela imagem desiderativa que, na terceira fase, servirá para valorar o que é percebido.

Analisemos então a disposição constituída nessa fase. A sexualidade perversa é a disposição da histeria de conversão e surgiu porque as mães não desejavam procriar pois, naquela época, devido aos escassos alimentos, muitos recém-nascidos morriam. Nos Três ensaios sobre a sexualidade (1905), Freud caracteriza a sexualidade infantil, perversa, como a busca da repetição de uma sensação de prazer associada a uma determinada imagem perceptiva; a criança busca repetir uma sensação que já fora anteriormente experimentada e que está registrada na memória. As imagens perceptivas que se associam ao prazer na memória podem ser tanto sensações táteis relacionadas com determinadas regiões do corpo (provocada pelo leite na boca, pela pressão do seio ou do dedo nos lábios, pela pressão das fezes no ânus ou pela pressão da mão no genital), como as imagens do objeto que executa a ação específica para o recém-nascido que é incapaz de executá-la, assim, por exemplo a imagem visual (ou mesmo sonora e tátil) da mãe, como é exposto no Projeto (1895) e no capítulo VII da Interpretação dos sonhos (1900). O que caracteriza a imagem, em todos esses casos, é que ela aparece no lugar da imagem motora que satisfaz o instinto e que não pode ser ocupada, disposição que, como vimos, foi constituída na primeira fase filogenética. É verdade que a busca da repetição da imagem tátil relacionada com o prazer implicará em novos movimentos (sugar, reter e soltar as fezes, masturbar-se), mas estes visam a repetir a recordação e não mais satisfazer o instinto. Como Freud expõe no Projeto, a imagem do objeto que auxilia a satisfação toma o lugar da ação, por isso o instinto não mais conduz à ação, mas à recordação que, freqüentemente, devido a sua intensidade, se apresenta como alucinação. Esse mesmo mecanis-

Revista de Filosofia, Curitiba, v. 17 n.20, p. 85-98, jan./jun. 2005. 
mo será depois exposto na obra de Freud, em O eu e o isso (1923), pela idéia de que o eu se apresenta como objeto para a satisfação do isso e, dessa forma, é investido pela libido.

Nessa fase filogenética se constitui o impulso sexual propriamente humano, caracterizado por sua plasticidade, por sua capacidade de ser determinado pelas próprias vivências contingentes e não pelo instinto biológico. Constitui-se a memória (formada pelas imagens percebidas nas vivências), não uma memória que serve à ação, mas que satisfaz o impulso, uma memória que corresponde à imaginação, à fantasia e que prescinde do mundo externo. Uma memória que servirá de base de comparação para todos os processos psíquicos posteriores.

A terceira fase filogenética corresponde à disposição para a neurose de compulsão e nela é concluída a psicologia do pai primitivo, que dá forma a si mesmo e a horda. Ele dá forma a si mesmo na medida em que a domesticação do instinto sexual dá forma ao eu. Nas palavras de Nietzsche trata-se de uma violação do eu animal "a matéria na qual se extravasa a natureza conformadora eviolentadora dessa força é aqui o homem mesmo, o seu velho Eu animal" (NIETZSCHE, 1887, p. 76).

Trata-se da violação praticada pelo artista, por meio da qual ele dá a si mesmo uma forma e cria a beleza.

Essa oculta violentação de si mesmo, essa crueldade do artista, esse deleite em se dar uma forma, como a uma matéria difícil, recalcitrante, sofrente, em se impor a ferro e fogo uma vontade, uma crítica, uma contradição, um desprezo, um não, esse inquietante e horrendamente prazeroso trabalho de uma alma voluntariamente cindida que a si mesma faz sofrer pelo prazer em fazer sofrer, essa má consciência ativa também fez afinal ... como verdadeiro ventre de acontecimentos ideais e imaginosos vir a luz uma profusão de beleza e afirmação nova e surpreendente, e talvez mesmo a própria beleza (NIETZSCHE, 1887, p. 76).

Nos termos de Freud, trata-se da própria constituição do eu. No Projeto de uma psicologia (1895), Freud descreve o eu como uma organização cuja energia é ligada e inibida na sua descarga, o eu dá forma ao psíquico na medida em que inibe a ação de movimento e a alucinação. No eu as quantidades se movimentam em direção às imagens desiderativas e isso constitui o pensamento. Pensar, portanto, é comparar a percepção e a recordação desejada, é a primeira espécie de avaliação, de

Revista de Filosofia, Curitiba, v. 17 n.20, p. 85-98, jan./jun. 2005. 
valoração do que é percebido. No pensamento são intensificadas as imagens de movimento que existem entre a imagem percebida e a desejada e a ocupação dessas imagens possibilita a transformação da imagem percebida na desejada. Essas imagens, portanto, possibilitam uma ação que transforma o mundo e assim o domina. As imagens de movimento próximas à imagem desiderativa são também importantes porque possibilitam a ampliação da atenção à percepção, tornando-a parcialmente independente do desejo. A percepção é agora comparada não com a imagem desiderativa, mas com uma imagem de movimento. Corresponde a esse processo a capacidade mimética, a capacidade de julgar um objeto percebido por meio da imitação de seu movimento. Corresponde também a capacidade de julgar (identificar) um objeto por meio de uma palavra, isto é, por meio de um som correspondente a uma imagem motora de articulação verbal. O pai primitivo é inventor da linguagem, pois cria imagens de movimentos produtoras de sons, com elas nomeia objetos e assim toma posse deles.

Também em Nietzsche as palavras, originalmente, funcionam como uma forma de apropriar-se das coisas.

O direito senhorial de dar nomes vai tão longe, que nos permitiríamos conceber a própria origem da linguagem como expressão de poder dos senhores: eles dizem 'isto é isto', marcam cada coisa e acontecimento com um som, como que apropriando-se assim das coisas (NIETZSCHE, 1887, p. 19).

O pai primitivo, no mito freudiano, se constitui sob o signo da força e da energia, cria leis invioláveis para si mesmo e cria a linguagem. É capaz de sublimação e cria a horda, a comunidade. Para Nietzsche também a mesma força que cria a interioridade cria, por meio de ações violentas, o Estado, dota de uma forma estável uma população sem normas e sem freio. Ele é, portanto, o primeiro credor, ao qual os filhos, por ele protegidos, passam a ter dívidas. Ele é também cruel e violento (analisaremos mais adiante essa característica).

A capacidade de criação do pai primitivo será na sexta fase filogenética, na qual ocorre o parricídio e que corresponde à disposição à mania-melancolia, em parte resgatada pelos filhos, quando eles devoram o pai e se identificam com ele. $O$ estado de mania da sexta fase do mito corresponde a esse resgate da psicologia do indivíduo, ou melhor, 
desse indivíduo livre, isento da passividade e do ressentimento dos filhos, poderoso, inventor da arte, da linguagem e formador da coletividade. São excluídos nesse resgate a crueldade e o sadismo que terão de encontrar nova forma de satisfação e esta será a culpa, nos termos de Nietzsche, uma câmara de autotortura, na suposição de Freud, aquilo que possibilita a manutenção da cultura.

Analisemos então a constituição da psicologia dos filhos, da psicologia que, em Psicologia das massas e análise do eu, Freud identificou como a psicologia das massas. Se até aqui a comparação com Nietzsche mostrou-se pertinente, na quarta fase filogenética tal comparação parece dar forma a uma série de elementos esparsos na teoria de Freud que, nessa fase, compõem uma totalidade.

Por um lado, toda a segunda parte do mito remete às neuroses narcisistas: demência precoce, paranóia e melancolia mania. $\mathrm{O}$ que caracteriza o narcisismo, disposição das neuroses narcisistas, desde o texto Introdução ao narcisismo (1914), é a idéia de que o impulso sexual passa a ter como referência não o impulso biológico não satisfeito, como vimos até agora, mas a dor. O órgão sexual é o órgão dolorido por excelência e a dor hipocondríaca, que funciona como uma dor de dente ou de um órgão na doença, é o protótipo da sexualidade. Auto-erotismo e narcisismo apresentam-se como um cuidado com o órgão dolorido, no caso com o órgão sexual, cuidado que exige o abandono de todas as ocupações objetais.

Por outro lado, na quarta fase filogenética, aparece o tema da castração. O pai cruelmente despoja seus filhos de sua virilidade pela castração, permitindo que permaneçam na horda como inofensivos trabalhadores. Tal fase determina uma parada no desenvolvimento do indivíduo e um retorno ao auto-erotismo.

Nessa fase, portanto, formam um conjunto de conceitos caros a Freud: dor, auto-erotismo (concebido como erotização da dor, portanto, como masoquismo), castração e relação com o pai.

Em relação à erotização da dor em Pulsões e seus destinos (1915) Freud afirma:

temos todos os motivos para aceitar que também a sensação de dor, assim como outras desagradáveis, alastram-se para a excitação sexual e produzem um estado completo de prazer, por essa razão pode-se também comprazer-se pelo desprazer da dor. (...) a sensação da dor se tornou uma meta masoquista (p.92).

Revista de Filosofia, Curitiba, v. 17 n.20, p. 85-98, jan./jun. 2005. 
A meta maso quista, constituída nessa fase, pode ser compreendida como uma disposição para a posição passiva perante ao pai, suposta em diversos textos de Freud. Em Psicologia das massas e análise do eu, por exemplo, Freud alude a herança arcaica para compreender a atitude passivo-masoquista perante o hipnotizador, os pais e o líder:

Por meio de suas medidas, o hipnotizador desperta no sujeito uma parte daquela herança arcaica que também veio de encontro aos pais e experimentou na relação com o pai uma reanimação individual, a representação de uma personalidade prepotente e perigosa, perante a qual apenas se pode colocar de forma passivo-masoquista, tendo de perder sua vontade, e estar sozinho com ela, "apresentar-se a ela", parece um sério risco. Apenas assim podemos imaginar a relação de um indivíduo da horda primitiva com o pai primitivo. (...) O líder da massa é sempre o temido pai primitivo, a massa quer sempre ser dominada pelo poder ilimitado, ela é no mais alto grau desejosa de autoridade, segundo a expressão de Le Bons, tem sede de submissão (p. 118).

Trata-se, portanto, da negação da própria vontade em prol do pai, por isso a extinção da libido e a posterior sexualização da dor.

A relação entre a castração e a submissão ao pai também se encontra em $\mathrm{O}$ homem Moisés e a religião monoteísta. O costume judeu da circuncisão faz reviver a castração que ocorria na horda primitiva, indicando, com isso, a submissão incondicional à vontade paterna:

Quando ouvimos que Moisés 'santificou' seu povo pela introdução do costume da circuncisão, então agora compreendemos o sentido profundo dessa afirmação. A circuncisão é o substituto simbólico da castração que o pai primitivo outrora infligira aos filhos na plenitude da perfeição do poder, e quem aceitava esse símbolo mostrava, com isso, que estava pronto para submeter-se à vontade do pai, também quando ele impusesse o sacrifício mais doloroso (p. 567).

O desejo de ser castrado pelo pai remete, também no caso Schreber (1911), ao desejo de ser mulher para o pai. Submeter-se à castração é submeter-se ao desejo paterno, a castração auto-infringida simboliza a idéia de ser desejado pelo pai. Portanto, o desejo de ser desejado pelo outro e a erotização da dor parecem ser as duas disposições herdadas dessa fase filogenética.

Revista de Filosofia, Curitiba, v. 17 n.20, p. 85-98, jan./jun. 2005. 
Aqui a comparação com Nietzsche é bastante frutífera. Retomemos a crueldade dos primeiros credores. Segundo Nietzsche, a dívida do devedor podia ser paga se esse concedesse ao credor o direito de lhe causar dor, o direito de ter a "satisfação íntima de poder descarregar no impotente seu poder", "de poder fazer o mal pelo simples prazer de fazer", enfim o credor sente-se reparado se lhe é concedido o "direito da crueldade". Essa crueldade é, por sua vez, imprimida no devedor por meio de "sacrifícios", "mutilações" e "castrações", por meio da dor, que passa a representar a memória da dívida.

A castração e a dor por ela infligida consistem, portanto, na recordação da dívida, nos termos de Freud, no amor ao pai devido à proteção que ele proporcionava. Mas a dor também é a forma de pagar a dívida, de satisfazer o sadismo do credor. Neste sentido, como contraparte do sadismo ela é sexualizada e transformada em masoquismo. A permanência na dor, portanto, não será a anulação da vontade, mas manifestação da vontade de ser objeto do pai, de satisfazê-lo.

Podemos dizer que depois do parricídio a oposição à insuportável "sociedade democrática de irmãos", na qual todos têm os direitos iguais, oposição expressa na reverência aos antepassados, na submissão às leis da sociedade, devido a motivos emocionais, na criação dos deuses, na criação de um único deus, na constituição das autoridades políticas, na constituição da família, enfim nas demonstrações de uma obediência posterior ao pai (Freud, Totem e tabu, 1912), têm como base a disposição passivo-masoquista.

O conceito de impulso (Trieb) de morte justificará, posteriormente, a crueldade e o sadismo paternos, o masoquismo dos filhos e também a culpa. Com esse conceito, no entanto, Freud se distancia bastante de Nietzsche, pois interpreta a crueldade não como vontade de poder, mas como uma tendência de retomo ao inorgânico, à morte.

Mas o que nos importa da quarta fase filogenética é que nela a dor passa a ser forma de pagamento da dívida e, portanto, manifestação do amor para com o pai. Por um lado, o direito de maltratar, de provocar dor nos filhos, possibilita que o pai os tolere, por outro lado, a submissão à dor é a forma dos filhos manterem sua relação com o pai. Em ambos os casos a dor é condição de novas relações objetais. A castração, por sua vez, nada mais é que o símbolo da dor.

Na quinta fase filogenética, os irmãos fogem da horda, identificamse entre si, devido à mesma situação de carência e de serem perseguidos pelo pai, e desenvolvem laços homossexuais uns com os outros. Certamente essa fase corresponde em Nietzsche à psicologia dos escravos,

Revista de Filosofia, Curitiba, v. 17 n.20, p. 85-98, jan./jun. 2005. 
dos homens fracos, ressentidos e reativos. Para Freud, é a situação de carência (os filhos que não se submetem à castração, mas, com isso, renunciam também a qualquer possibilidade de satisfação) que produz o processo de identificação e o surgimento de laços sexuais inibidos em sua finalidade, no caso, homossexuais. Assim, como a criança passa a amar o irmão antes odiado apenas quando percebe que nenhum deles terá o amor exclusivo dos pais, assim também, a ameaça de castração, a ameaça da dor, a carência, faz com que os irmãos identifiquem-se uns com os outros e passem a se amar porque o outro lhe parece um semelhante (já no Projeto Freud vincula a compaixão à vivência de dor).

Na sexta fase, os irmãos, até então fracos, unidos tomam-se fortes, retomam e matam o pai. Identificam-se com ele no seu aspecto criativo e no seu aspecto violento, mas a violência volta-se para si mesmo, identificam-se também com o pai em seu aspecto odiado, característica que intensificará 0 masoquismo já constituído na quarta fase. Para Freud, só nessa fase surge a cultura, propriamente dita, ela é uma criação dos fracos, dos ressentidos, mas que unidos se sentem e se tomam fortes. Essa origem da cultura permite-nos pensá-la como um resgate parcial da psicologia do indivíduo pelas massas, originalmente, passivas e ressentidas. Resgate que terá como conseqüência uma hierarquização do aparelho psíquico, não só dos impulsos, como ocorre na constituição da psicologia do pai primitivo, mas uma hierarquização do próprio eu que por meio da culpa passa a ser carrasco de si mesmo. Por meio dessa hierarquização, a crueldade retorna sobre si mesmo, possibilitando a manutenção da sociedade, coisa que não era possível na horda. Os filhos, assim como o pai, foram cruéis e praticaram um crime. A diferença entre ambos é que no caso dos filhos, devido aos laços com os outros irmãos, a crueldade tem de ser reprimida e, devido ao masoquismo, ela retoma para si mesmo na forma de culpa. Só aqui para Freud surge a ambivalência.

\section{Conclusões finais}

Tendo mostrado que as concepções de Freud do mito filogenético da era glacial têm como ponto de partida as concepções de Nietzsche sobre a formação da cultura, podemos ainda afirmar que a hipótese do parricídio, proposta por Freud já em Totem e tabu, deve ser compreendida como um elo que completa a genealogia da moral construída por Nietzsche. Em Totem e tabu Freud busca explicar justamente a ambiva- 
lência para com os antepassados, que é apontada na teoria de Nietzsche, mas não interpretada (pelo menos do ponto de vista freudiano). De acordo com Nietzsche, a mesma relação que o devedor tem com credor, ele tem posteriormente com a comunidade. A comunidade pune cruelmente aqueles que esquecem de sua dívida para com ela. Por outro lado, quanto mais a comunidade torna-se forte, mais cresce o sentimento de dívida para com os antepassados, com aqueles que imprimiram forma na comunidade (o que justifica a criação de deuses cada vez mais poderosos à medida que aumenta o poder da comunidade). Do ponto de vista freudiano, podemos supor que falta um elo intermediário nessa passagem, elo que justifique a ambivalência. Por que razão quanto mais forte torna-se a comunidade, isto é, quanto mais credora perante outras comunidades ela se torna, mais devedores perante aos antepassados tornam-se seus participantes (quanto mais credores, mais devedores os membros da comunidade se tornam)? Para Nietzsche trata-se de uma reverência àqueles que formaram a comunidade. Para Freud, no entanto, podemos supor a intensificação do débito para com o antepassado a cada crédito alcançado perante as outras comunidades nada mais revela que uma dívida impagável com o antepassado, dívida por tê-lo assassinado. Desde o princípio, a dívida, para Freud, diferente de Nietzsche, é impossível de ser resgatada e cada vitória da comunidade a recorda e a intensifica. Assim, se supusermos que a análise da ambivalência é o fio condutor de Totem e tabu - no primeiro ensaio, a análise da ambivalência para com os objetos incestuosos, repudiados, no entanto, desejados; no segundo ensaio, a análise da ambivalência para com os inimigos, odiados, mas reverenciados, e da ambivalência para com os heróis (que matam os inimigos), para com as autoridades e para com os antepassados mortos, todos eles reverenciados, mas mal tratados; no terceiro ensaio, a análise da ambivalência como origem da religião e, por último, no quarto ensaio a justificação da ambivalência pela hipótese do parricídio - podemos supor que já nesse texto Freud busca interpretar as hipóteses de Nietzsche que, apesar de relacionar a reverência aos antepassados com a dívida (Schuld), considera-a isenta de valor moral (só posteriormente, para Nietzsche a dívida terá valor moral e tornar-se-á efetivamente culpa). Para Freud, desde o início a dívida é moral, pois ela é um ato de violência executado pelos fracos, pelos escravos, pelos ressentidos, no entanto, ela é necessária (a culpa é necessária) para que os fracos tornem-se fortes, sem se tornarem, na mesma medida, violentos.

Revista de Filosofia, Curitiba, v. 17 n.20, p. 85-98, jan./jun. 2005. 
Referências

FREUD, Sigmund. Projeto de uma psicologia. Tradução de Osmyr Faria Junior. Rio de Janeiro, RJ: Imago. 1995.

.Três ensaios sobre a teoria sexual. Drei Abhandlungen zur Sexualtheone. Studienausgabe. Frankfurt am Main: Fischer Taschenbuch, 1982. Band 5.

. Observações psicanalíticas sobre um relato autobiográfico de um caso de paranóia. Psychoanalytische Bemerkungen über einen autobiographisch beschriebenen Fall von Paranoia. Studienausgabe. Frankfurt am Main: Fischer Taschenbuch, 1982. Band 8.

. Totem e tabu. Totem und Tabu. Studienausgabe. Frankfurt am Main: Fischer Taschenbuch, 1982. Band 9.

. Uma introdução ao narcisismo. Zur Einführung des Narzissmus. Frankfurt am Main: Fischer Taschenbuch, 1982. Band. 3.

. Pulsões e seus destinos. Triebe und TriebsSchicksale. Studienausgabe. Frankfurt am Main: Fischer Taschenbuch, 1982. Band 3. İmago, 1987.

. Neuroses de Transferência: uma síntese. Rio de Janeiro, RJ:

Além do princípio do prazer. Jenseits des Lustprinzips. Studienausgabe. Frankfurt am Main: Fischer Taschenbuch, 1982. Band 3.

. Psicologia das massas e análise do eu. Massenpsychologie und IchAnalyse. Studienausgabe. Frankfurtam Main: FischerTaschenbuch, 1982. Band 9.

. 0 eu e o id. Das Ich und das Es. Studienausgabe, Band III. Frankfurt am Main: Fischer Taschenbuch Verlag, 1982.

Mal estar na cultura. Das Unbehagen in der Kultur. Taschenbuch. Frankfurt am Main: Fischer Taschenbuch, 1982.

. O homem Moisés e a religião monoteísta. Der Mann Moses und die monotheistiche Religion. Studienausgabe. Frankfurt am Main: Fischer Taschenbuch, 1982. Band. 9.

NIETZSCHE, Friedrich Wilhelm. Genealogia da moral. São Paulo, SP: Companhia das letras. 1998.

Recebido em: Received in: 21/02/ 2005 Aprovado em: Approved in: 25/03/2005 